\title{
EL KESTOS HIMAS, LA GRAN JOYA DE AFRODITA
}

\author{
Elena Almirall Arnal \\ Universitat de Barcelona
}

\begin{abstract}
Este artículo reflexiona sobre las joyas como armas de seducción de las mujeres griegas y, concretamente, sobre las de Afrodita, una divinidad multifacética cuya acción prioritaria se enmarca dentro del ámbito de la sexualidad y el amor. La diosa posee un ornamento mágico, el kestos himas, en cuya superficie están bordadas algunas de las emociones humanas como el deseo, la seducción y el amor. Dicha joya es la protagonista de algunos episodios muy interesantes de la literatura griega, especialmente el conocido como Dios Apate o el engaño de Hera para seducir a Zeus.

PALABRAS CLAVE: Afrodita, joyas, seducción, patriarcado, Hera, subversión.
\end{abstract}

\section{The Kestos Himas, Aphrodite's Great Jewel}

This essay reflects on jewels as means of seduction for Greek women and, specifically, on those of Aphrodite, a multifaceted deity whose main action is framed within the sphere of sexuality and love. This goddess is the owner of a magical ornament, the kestos himas. On its surface are embroidered some human emotions like desire, seduction and love. This jewel has a leading role in some very interesting episodes of Greek literature, especially the one known as Dios Apate or Hera's deception of Zeus in order to seduce him.

KEY WORDS: Aphrodite, jewels, seduction, patriarchy, Hera, subversion.

Cuéntame, Musa, las acciones de la muy áurea Afrodita, de Cipris, que despierta en los dioses el dulce deseo y domeña las estirpes de las gentes mortales, a las aves que revolotean en el cielo y a las criaturas todas, tanto a las muchas que la tierra firme nutre, como a cuantas nutre el ponto. A todos afectan las acciones de Citerea, la bien coronada.

-Himno homérico a Afrodita: v, 1-7

La diosa Afrodita no necesita presentación. Es una de las grandes divinidades del panteón olímpico, reverenciada en toda Grecia por ser la diosa de la belleza, del amor y de la fertilidad. Sin embargo, basta leer las fuentes con un poco de profundidad para descubrir que es bastante más que eso, que es una diosa con infinidad de matices y cuyo rol en la religión y el imaginario griego clásico es mucho más complejo.

Como sucede con gran parte de los mitos griegos, existen dos versiones del relato de su nacimiento. Por un lado, la versión de Hesíodo (Teogonía, 155 ss.) que explica 
cómo la diosa surgió del esperma de Urano, cuyos genitales habían sido cortados y arrojados al agua por su hijo Crono; por otro lado, la versión homérica que aparece en la Ilíada $(\mathrm{v}, 370)$ y que la presenta como hija de Zeus y Dione.

En el siglo $\mathrm{V}$ a.C., Platón dará una explicación "práctica" a este doble origen, en su diálogo El banquete (180d ss.), señalando que existen dos Afroditas: ${ }^{1}$ una es hija de Urano y, por este motivo, se la llama Urania; la otra, más joven, es hija de Zeus y Dione, y es conocida como Pandemos. ${ }^{2}$ Con esta teoría, el filósofo explica que hay dos formas de amar diferentes: una que es noble y eleva las almas y otra que es ordinaria, siente atracción por el placer y refuerza los vínculos que unen el alma al cuerpo. La primera está a cargo de Afrodita Urania, la segunda pertenece al ámbito de Afrodita Pandemos. Así pues, la explicación de Platón contempla un amor dual: uno sería el virtuoso (Urania) o aquél que procede de la diosa en cuyo nacimiento no ha intervenido mujer; y el otro, el vulgar (Pandemos), que surge de una relación entre ambos sexos. Además, este último, el amor de Afrodita Pandemos, está relacionado con la práctica sexual - tanto entre hombres como entre hombres y mujeresmientras que el amor procedente de Urania, representa el amor intelectual y solo se encuentra en las relaciones entre hombres (Alzard, 2013: 23). Para el filósofo, el único amor "digno de ser alabado" es el que "nos induce a amar bellamente" y ese es, evidentemente, el que procede de la diosa Urania:

El otro, en cambio, procede de Urania, que, en primer lugar, no participa de hembra, sino únicamente de varón - y es éste el amor de los mancebos-, y, en segundo lugar, es más vieja y está libre de violencia. De aquí que los inspirados por este amor se dirijan precisamente a lo masculino, al amar lo que es más fuerte por naturaleza y posee más inteligencia. (Pl., Smp., 181c)

Ambas Afroditas están plenamente representadas en la polis pues, como explica Pirenne-Delforge (1994), en la ciudad de Atenas existieron templos diferenciados para ambas, siendo distintos también sus rituales y ceremonias.

Como ya hemos señalado, las entidades primordiales que se materializan en las divinidades griegas son de una gran complejidad. Afrodita nace como una manifestación singular de esta realidad. Sostiene Jean Rudhardt que las dos versiones del nacimiento de la diosa responden a dos momentos diferentes: por un lado, Hesíodo describe un mundo en formación, en el que viven un número limitado de seres inmensos y muy poderosos cuya figura es imprecisa. Por otro lado, el universo homérico está habitado ya por "criaturas bien individualizadas que ocupan cada una

\footnotetext{
${ }^{1}$ Dos aspectos de la misma diosa, según Burkert (2007: 210).

${ }^{2}$ Pandemos significa, literalmente, "aquella a la que todo el pueblo adora". Como señala Flacelière (1971: 43) se trataba, sin duda, de una diosa cívica.
}

50

Lectora, 26 (2020): 49-65. ISSN: 1136-5781 D.O.I.: 10.1344/Lectora2020.26.4 
el lugar que conviene en un orden que Zeus ha impuesto al mundo, que es su reino y lo mantiene" (Rudhardt, 1986: 23). En este universo ordenado, el amor es engendrado por las cualidades de la persona que lo inspira; en él, la belleza y la atracción juegan un papel predominante.

Así pues, a medida que el mito de Afrodita se va desarrollando en el imaginario griego, vemos como la diosa adopta muchos aspectos y no solo está relacionada con la sexualidad. Aparece también como diosa ctónica, como homicida, se la relaciona con la guerra, ${ }^{3}$ etc. Concretamente, Paul Friedrich (1978: 73) ha destacado dieciocho dimensiones diferentes en las que se puede incluir a esta diosa multifacética cuyos dones son ambiguos y cuya actuación provoca, tanto en las divinidades como en los seres humanos, estados anímicos que van desde el anhelo hasta los celos, causando estragos y desencadenando todo tipo de enfrentamientos.

Y, sin embargo, su mismo nombre designa su esfera de intervención prioritaria: aphrodisiázein significa hacer el amor, ${ }^{4}$ las aphrodisia son las obras de Afrodita, y su empleo se refiere a los actos, los gestos, los contactos que procuran una cierta forma de placer. "La experiencia erótica está vinculada, por su misma designación, a la intervención de la diosa en el mundo" (Pirenne-Delforge, 1994: 432).

\section{Las joyas de Afrodita, armas de seducción y poder}

Una vez establecida la complejidad de esta diosa y sus múltiples atribuciones, pasemos a centrarnos en el tema que nos ocupa: sus joyas y, concretamente, el kestos himas.

En las múltiples presentaciones de Afrodita mencionadas en las fuentes griegas, la diosa siempre aparece enjoyada. Se habla de su belleza, de su vestimenta y, sobre todo, se destacan sus múltiples alhajas. De hecho, uno de sus epítetos principales es "la dorada": "Llevaba retorcidas espirales y brillantes pendientes en forma de flor. Primorosos eran los collares en torno a su delicada garganta, hermosos, de oro, totalmente cincelados" (h. Hom., h. Ven.).

Todos estos atributos son las armas de seducción de la diosa, a cuyo poder no se pueden sustraer ni las divinidades ni los seres humanos. ${ }^{5}$ Incluso el mismo Zeus, poderoso guardián del orden del universo, se ve a menudo afectado por las maniobras

\footnotetext{
${ }^{3}$ Sobre la relación de Afrodita con la guerra, véase Iriarte y González (2010), que analizan la relación de la diosa con Ares, así como los nexos entre sus campos de acción, entre violencia y erotismo.

${ }^{4}$ Para más información sobre este tema, véase Burkert (2007: 206).

${ }^{5}$ A pesar de eso, en el Himno homérico a Afrodita se explica que hay una excepción, existen tres diosas que no se ven afectadas por sus artimañas: Atenea, Artemis y Hestia ("A los corazones de estas no las puede persuadir ni engañar”, p. 188). Como apuntan Baring y Cashford, las únicas diosas que se pueden resistir a las maniobras de la diosa son aquellas "cuyas esferas de poder están delimitadas de forma muy precisa" (2005: 403).
} 
de Afrodita: "Ella le arrebata el sentido incluso a Zeus que se goza con el rayo, él que es el más grande y el que participa del mayor honor" (h. Hom., h. Ven.).

Según María Dolores Mirón, en la sociedad griega "que valoraba tanto las virtudes físicas como espirituales, la belleza formaba parte de las cualidades fundamentales del modelo de mujer ideal" (2007: 167). Parte importante de esta belleza la constituyen la vestimenta y las joyas, que realzan el atractivo de las mujeres y reafirman su poder seductor, el único posible para ellas (Mirón, 2007). Cuando Hesíodo describe la creación de Pandora, madre de la "raza de las mujeres", explica cómo Zeus ordena a Hefestos que mezcle tierra y agua, le infunda voz y vida humana y haga una figura "linda y encantadora", semejante a las diosas inmortales. Atenea le mostrará sus labores y la "dorada Afrodita" rodeará su cabeza de gracia, irresistible sensualidad y halagos cautivadores; finalmente, Hermes la dotará de una mente cínica y un carácter voluble. Pandora es engalanada con ceñidores, collares y todo tipo de aderezos (Op., 60-83). Así pues, para ser seductora, la mujer no solo tiene que ser bella sino, además, estar engalanada con alhajas y atributos prácticos. Plutarco aporta información adicional sobre cómo debe ser una esposa legítima:

Así pues, una cosa invencible es una esposa legítima, si, teniendo depositadas en su persona todas las cosas, la dote matrimonial, el linaje, los hechizos y el mismo cinturón de Afrodita, procura el afecto de su marido con su moral y su virtud. (Plu., Mor. II, 23)

En una cultura como la helena, en la que el matrimonio es prácticamente una transacción comercial, "las joyas formaban parte esencial del atuendo de la novia griega, símbolo de su atractivo tanto sexual como económico” (Mirón, 2007: 175).

Por lo tanto, las alhajas eran armas de seducción y una mujer adornada con ellas era una mujer peligrosa porque estaba ejerciendo su poder. Veremos más adelante como Hera, en el famoso episodio conocido como Dios Apate, ${ }^{6}$ se embellecerá, con la ayuda de Afrodita, para seducir a Zeus. No hay duda de que Hera es una diosa bella - es una de las tres competidoras por la célebre "manzana de la discordia" para la más hermosa- pero aun así, tras años de matrimonio, se ve obligada a recurrir a las joyas, en concreto al kestos himas de Afrodita, para cautivar a su marido.

Este poder femenino es atrayente y necesario porque es parte fundamental de las necesidades de reproducción de los habitantes de la polis; pero, por otro lado, es peligroso pues trastoca el orden. Como explica Michel Foucault (2003: 30), en la

\footnotetext{
${ }^{6}$ Dios Apate o "el engaño de Zeus" es el nombre dado por los editores antiguos a un episodio de la Ilíada, en concreto del Libro XIV, líneas 153-353, en el que Hera engaña a su marido para seducirlo, dormirlo y poder participar en la Guerra de Troya a favor de los aqueos, algo que el Crónida le había prohibido.
}

52

Lectora, 26 (2020): 49-65. ISSN: 1136-5781 D.O.I.: 10.1344/Lectora2020.26.4 
sexualidad griega existiría una dualidad entre el sujeto y el objeto, entre el agente y el paciente. Basándose en Aristóteles, Foucault afirma que, para los griegos, la mujer era el elemento pasivo, mientras que el hombre era el activo.

En esta misma línea, y en lo que se refiere a la reproducción, Judith Butler apunta que "se dice que la mujer aporta la materia y el hombre la forma. La hyle griega es la madera que ya fue cortada del árbol, instrumentalizada e instrumentalizable, un artefacto, en el sentido de estar disponible para su uso" (2010: 60).

Por lo tanto, en el pasaje mencionado de la Ilíada, Hera subvertirá el orden sexual correcto, pasando de ser objeto pasivo a ser sujeto activo. Y veremos cómo el kestos himas de Afrodita es el elemento - la joya- que tiene el poder de alterar dicho orden, de transformar a las mujeres de pasivas a activas. De ahí que sea una diosa amada pero también temida, porque su poder desequilibra la armonía instaurada por Zeus al crear el matrimonio. Hera, esposa divina en esta unión ejemplar y diosa de la institución matrimonial, engaña a su esposo con artificios y argucias. En el mundo griego, esto está mal visto y, como sucede en este ejemplo, el marido le acabará imponiendo un castigo ejemplar. No olvidemos el carácter moralizante de la mitología griega.

\section{El kestos himas}

Entre todas las joyas de Afrodita destaca el kestos himas, dos palabras sobre cuya traducción no hay un acuerdo. La palabra himas ha sido interpretada como collar, cinturón, correa, ceñidor e incluso como "saltire", 8 mientras que kestos suele traducirse como bordado. ${ }^{9}$ Para Mireille Lee:

era una banda que se cruzaba en el pecho y su significado ha sido objeto de mucha especulación. Por un lado, tenía una función práctica, la de conseguir que el vestido se mantuviera bien colocado y sin ondulaciones (por eso lo llevan figuras activas como Atenea y Artemis), pero, por otro lado, también tenía una función erótica que era la de enfatizar el pecho femenino. (2015: 138)

Teniendo en cuenta la controversia que existe sobre este tema, en este artículo hemos decidido mantener el término griego para no dar lugar a confusión, excepto cuando utilicemos un texto que lo traduzca.

\footnotetext{
${ }^{7}$ Para los griegos, hyle es la materia como corporeidad y posibilidad de la cual están hechas todas las cosas.

${ }^{8}$ El "saltire" o cruz de San Andrés es un símbolo heráldico en forma de cruz en diagonal.

${ }^{9}$ Para más información sobre este tema, véase: Faraone (1990), Bonner (1949) y Brenk (1998).
} 
Existen referencias al kestos himas en documentos de todas las épocas de la Antigüedad, desde los poemas homéricos hasta la literatura bizantina. ${ }^{10}$ Como sucede con otras joyas mencionadas en las fuentes griegas, a medida que avanzamos en el tiempo, la descripción de este ornamento va evolucionando, pero siempre mantiene sus atributos mágicos, pues se trata de una alhaja que pertenece a la diosa Afrodita y cuya principal virtud es que despierta el amor y el deseo de todos los hombres por la mujer que lo lleva puesto. Según James Redfield, es el emblema del poder sexual de las mujeres. "El cinturón de Afrodita contiene oaristus parphasis (Il. XIV, 216), un hablar dulce que encandila la mente, y ella presume de su oarous kai meteis, lenguaje y artimañas dulces, con los que une a los inmortales con mujeres mortales y los somete a su voluntad (h. Ven.)" (Redfield, 2003: 72-73).

Tal vez la referencia más conocida sobre el himas es la que aparece en la Ilíada XIV y que ya hemos mencionado. En este fragmento, la diosa Hera pretende embaucar a Zeus para que se acueste con ella y, después de acicalarse con múltiples joyas y perfumarse con aceites, le pide a Afrodita que le de "el amor y el deseo con el que a todos los inmortales y a las mortales gentes tú doblegas" (198-199). La excusa que esgrime Hera es que, con el mágico objeto, desea poner fin a las querellas de Océano y Tetis para que se unan en el amor pero, en realidad, su intención es seducir a Zeus y adormecerlo para poder intervenir en la Guerra de Troya a favor de los aqueos. Por lo tanto, el primer engaño va dirigido a Afrodita, a quien la diosa miente para conseguir sus propósitos. Afrodita accederá a sus deseos:

Díjole, a su vez, la risueña Afrodita:

"Ni es posible ni estaría bien negarse a lo que pides.

Tú eres quien pasa la noche en los brazos del supremo Zeus".

Dijo, y del pecho se desató la recamada correa

bordada, donde estaban fabricados todos sus hechizos:

allí estaba el amor, allí el deseo, allí la amorosa plática,

la seducción que roba el juicio incluso a los muy cuerdos.

Se lo puso en las manos, la llamó con todos sus nombres y dijo:

"Toma ahora, métete dentro del regazo esta correa

bordada en la que todo está fabricado. Y te aseguro que no

regresarás sin haber realizado lo que tus sentidos anhelan”.

(Hom., Il., XIV, 211-221)

\footnotetext{
${ }^{10}$ Baring y Cashford (2005: 403) señalan que "el cinto bordado" de Afrodita recuerda al de la diosa sumeria Inanna que, más tarde, aunque con un significado transformado por el fervor, será el de María. Curiosamente, el Santo Cinto de la Virgen María también está asociado a milagros, en este caso de curación de la infertilidad o relacionados con el embarazo de las mujeres.
}

54

Lectora, 26 (2020): 49-65. ISSN: 1136-5781 D.O.I.: 10.1344/Lectora2020.26.4 
En este fragmento se plantean varios temas interesantes: uno de ellos es el doble engaño de Hera que recibirá, más adelante, su castigo. Aunque, inicialmente, consigue embaucar a Zeus a quien "nada más verla, el amor le envolvió las sagaces mientes, como la primera vez que se habían unido en el amor, cuando ambos acudieron al lecho a escondidas de sus padres" (294-296). Después, cuando el dios se despierta y descubre la traición de su esposa, la amenaza con azotarla y le recuerda que tiempo atrás la suspendió de los pies como castigo, afirmando seguidamente que le volverá a hacer lo mismo para que ceje en sus engaños (XV, 4-33). De esta forma, el dios vuelve a restaurar el orden patriarcal que Hera había querido truncar.

Aun así, es importante remarcar que este episodio muestra cómo la sexualidad puede ser explotada para conseguir objetivos diferentes al amor: al seducir a Zeus, Hera logra eludir su prohibición de intervenir directamente en Troya y lo cautiva gracias a la forma en que se presenta ante él. Este elemento de intención oculta por parte femenina es una característica común del estereotipo de la vestimenta (Brown, 1997). Hera no pretende conseguir el amor de Zeus sino que utiliza el encantamiento para obtener un objetivo puramente sexual y poder, así, intervenir en la guerra.

Es interesante destacar también que Christopher Faraone (1990: 227-229) considera que el episodio del encuentro entre Hera y Afrodita es un ejemplo de cómo podían ser las plegarias habitualmente asociadas con los amuletos y que, además, parece reflejar un ritual tradicional realizado por las mujeres recién casadas para evitar cualquier futura discordia en su matrimonio.

Finalmente, debemos comentar el hecho de que Afrodita posea un ornamento, una correa, un cinto o una banda en el que están todos sus hechizos. Cabe preguntarse, entonces, si los poderes de seducción de Afrodita le son connaturales o están subordinados a su posesión del kestos himas. No es algo que quede claro. Para Barbara Breitenberger (2007: 74) es evidente que ella es la propietaria del amor y del deseo puesto que gracias al himas los puede transferir; así, puede prestarlos a otras deidades o los puede utilizar para sus propios propósitos. Sin embargo, María Dolores Mirón propone que quizás la belleza de espíritu de las mujeres — es decir, su belleza internano existía "y había de ser adornada, como su cuerpo, de virtudes morales que no le eran del todo intrínsecas" (2007: 175). Esta afirmación conllevaría la idea de que el único poder de las mujeres, entonces, no es tal y que depende de aditamentos externos, algo que no sería de extrañar en el ideario masculino de la Grecia Antigua. Tal vez, esto podría extrapolarse a Afrodita y su kestos himas, el hecho de que los poderes no fueran suyos sino que perteneciesen en realidad a uno de sus ornamentos, resultaría sin duda tranquilizador para el hombre griego. Sin esta joya, no tendría esa fuerza que a todos trastorna.

Sea como sea, el kestos himas de Afrodita tiene el efecto, como otros objetos mágicos, de transformar en activas a las pasivas mujeres, y que, de esta manera, sean parte dinámica en el acto amoroso: les da el poder de decir cómo, cuándo y por qué. 
Debemos recordar que en la mentalidad griega antigua, el amor no es un acto de la voluntad que surge del interior de la persona sino una fuerza externa que la invade (López Jimeno, 2000). El efecto que tiene en Zeus - "Nunca hasta ahora tan intenso deseo de diosa o de mujer me ha inundado el ánimo en el pecho hasta subyugarme" (Il., XIV, 315-316) - es un ejemplo. Pero, como ya hemos comentado, no solo es utilizado por las divinidades sino también por los seres humanos. Encontramos prueba de ello en un poema de Antífanes recogido en la Antología Palatina:

Afrodita es tu aliada

Citerea misma soltóse de sus senos el ceñidor que suscita los deseos, y a ti lo entregó, Ino, para que lo tuvieras, de forma que siempre pudieras subyugar con sus seductores filtros a los hombres: todos los has usado contra mí solo. $(A P, 13)$

En este caso, el enamorado siente que está cautivado por Ino debido a que ésta posee el "ceñidor" de la diosa.

Sobre el poder de Afrodita destaca también uno de los poemas de Safo, quien suplica a la diosa que no someta a su corazón:

Inmortal Afrodita de bien labrado trono, hija de Zeus trenzadora de engaños, yo te imploro, con angustias y penas no esclavices mi corazón, Señora, ven en vez de eso aquí, si en verdad ya otra vez mi voz oíste desde lejos y me escuchaste y abandonando la mansión del padre viniste, el áureo carro luego de uncir: bellos, veloces gorriones te trajeron sobre la tierra negra batiendo con vigor sus alas desde el cielo por en medio del éter. Presto llegaron: y tú, diosa feliz, sonriendo con tu rostro inmortal me preguntabas qué me sucedía y para qué otra vez te llamo y qué es lo que en mi loco corazón más quiero que me ocurra: “¿A quién muevo esta vez a sujetarse a tu cariño? Safo, ¿quién es la que te agravia? Si ha huido de ti, pronto vendrá a buscarte; si no acepta regalos, los dará; si no te ama, bien pronto te amará aunque no lo quiera”. Ven, pues, también ahora, líbrame de mis cuitas rigurosas y aquello que el corazón anhela que me cumplas, cúmplemelo y tú misma sé mi aliada en la batalla. (Sapph., I, 1$)^{11}$

Este fragmento ha servido, en ocasiones, como argumento para evidenciar la dimensión bélica de Afrodita, pues en él destacan el uso de palabras relacionadas con la guerra (huir, perseguir, batalla). Así, Gabriella Pironti (2005) afirma que no está de acuerdo con Vernant, quien la presenta como una diosa de la paz, y opina que a pesar

\footnotetext{
${ }^{11}$ Para los poemas de Safo hemos utilizado la versión de Gredos, traducida por Rodríguez Adrados (1980).
} 
de que Afrodita está en el mundo opuesto de Ares -él se ocupa de los hombres y de la guerra y ella de las mujeres y del matrimonio- se trata de una oposición complementaria. En este sentido, Pirenne-Delforge propone que la detallada explicación que se hace de Hera cuando se está acicalando para seducir a su esposo es similar a la preparación de un guerrero antes de la batalla:

Sus preparativos se describen minuciosamente y, en la descripción del poeta, no se deja de lado ninguna etapa de la estrategia divina, y sobre todo femenina. Peinado, ropa, perfumes, joyas, el equipamiento de la esposa ansiosa por complacer no tiene nada que envidiar al de un soldado dispuesto para el combate. (1994: 278)

Las batallas femeninas, pues, se luchan en el ámbito de la alcoba y Afrodita es la diosa que las encabeza, igual que Ares es quien preside las guerras masculinas. Cada una de estas divinidades dispone de los elementos necesarios para su combate concreto, el kestos himas es el de Afrodita. De hecho, cabe señalar que la palabra himas se utiliza también en la Ilíada para designar las correas del casco de un guerrero o las riendas de los caballos. "Se trata entonces bien de una correa, de un vínculo que puede ser usado para 'domar' a un animal, como Afrodita 'doma' a los mortales y a los inmortales” (Pirenne-Delforge, 1994: 279), según las palabras que utiliza Hera.

Ana Iriarte y Marta González (2010) señalan que la persuasión erótica es, como la fuerza bruta, una forma de doblegar e imponer el propio criterio y que, aunque no son equivalentes, sí que fueron comparadas por los griegos como fuerzas que actúan, en el seno del matrimonio, en beneficio de una de las partes. Unas serían, pues, armas femeninas y, otras, armas masculinas en una cultura que entendía el amor como un combate. En palabras de Kate Millett, "el dominio sexual es tal vez la ideología más profundamente arraigada en nuestra cultura, por cristalizar en ella el concepto más elemental del poder. Ello se debe al carácter patriarcal de nuestra sociedad y de todas las civilizaciones históricas" (1995: 70).

Otros autores clásicos que mencionan el kestos himas son Aneo Cornuto, quien observa que la alhaja de Afrodita "tiene el poder de unir y atar a uno con lo otro" (Sobre Afrodita, 24.46); Plutarco que, en Moralia, utiliza el episodio del cinturón para explicar que dichos artificios y descaro no son propios de una mujer casada (Moralia, "Si hay que filtrar el vino", 2, 660); el sofista y orador Elio Aristides hablará de los fármacos de la diosa con los que ata a todos los hombres a ella (Ístmico a Posidón, 25); y Luciano relacionará el cinturón con la elección de Afrodita por parte de Paris en su famoso juicio pues, según él, la diosa Atenea le dice:

Que no se desnude ella la primera, Paris, antes de quitarse el cinturón —es una bruja-, no sea que te hechice con él. Por cierto, que debería comparecer sin tantos adornos ni tantos coloretes como si fuera auténticamente una 
fulana, sino que debería mostrar su belleza al natural. (Luc., Juicio de diosas, $35,10)$

De nuevo aparece aquí la idea de que, para seducir, una mujer griega -incluida Afrodita - se adornaba y se maquillaba, es decir, se preparaba para su "guerra" particular. En este caso, la diosa virgen, Atenea, lo plantea como una crítica. Ella, que se caracteriza por su autonomía y su virginidad, es lo opuesto de Afrodita, quien destaca por su belleza física y su seducción sexual. Atenea representa los valores patriarcales, Afrodita, en cambio, la posibilidad de subvertirlos. Como ya se ha comentado, el mito perpetúa las relaciones de poder y el discurso patriarcal. Dunia Alzard afirma que "Afrodita acaba con la idea de mujer dominada al convertir el acto sexual en un símbolo de situación en el que subvierte los roles”, pues es una diosa que "disfruta de su sexualidad y la reivindica, negándose al papel pasivo que la cultura androcéntrica otorga a las mujeres” (2013: 26).

El filósofo Temistio menciona también el kestos himas en varios de sus discursos políticos (Discurso de la embajada pronunciada en Roma, 48b; El amor fraterno, 84a; Agradecimiento al emperador por la paz y por el consulado del general Saturnino, 209b; De la inclinación del príncipe a escuchar al filósofo, 218d); a su vez, el poeta épico Coluto se refiere a él cuando habla del rapto de Helena: "el ceñidor de donde las mujeres toman el pinchazo de mi pasión y muchas veces sufren, aunque no mueran" (93-97); el historiador Teofilacto Simocates afirma que "placer y dolor van mezclados y los Amores gozan causando sufrimientos: de muy varios sentimientos está bordado el cinturón de Afrodita" (Epístolas, 84). Finalmente, el kestos himas aparece en la literatura bizantina, concretamente en el poeta Pablo Silenciario o en el historiador Agatías Escolástico.

Sin embargo, existe una fuente que proporciona una descripción más concreta sobre el kestos himas. Se trata de un texto del siglo IV-V perteneciente a las Dionisíacas de Nono de Panópolis. En él, su autor recupera el episodio del Dios Apate pero, además, ofrece todo tipo de detalles sobre el ornamento mágico que poseía Afrodita y que tanto interés literario ha suscitado:

Y habiendo hablado así la convenció y Afrodita la de mente astuta obedeció pérfidamente y, quitándoselo de su regazo, le entregó a Hera como regalo el cesto de los Amores y le dijo estas palabras sobre el don de aquel amoroso ceñidor: "Recibe este ceñidor como ayuda contra tu desgracia. Hechizarás todas las cosas con este cesto tan solo, que gobierna el deseo: a Helio, a Zeus, a Éter y al coro de las estrellas, e incluso la corriente del Océano infinito”. Así habló y se ocultó tras una roca del Líbano asirio. Hera marchó al contorno estrellado del Olimpo, y al punto se dispuso a adornar su blanquísima figura. Sin cesar igualaba y fijaba el contorno de su rostro y ponía en orden los

58

Lectora, 26 (2020): 49-65. ISSN: 1136-5781 D.O.I.: 10.1344/Lectora2020.26.4 
bucles cambiantes de su cabellera revuelta. Tras lavarse la cara, se cubrió con una túnica brillante y la anudó con una fíbula, cierre de su quitón. Se ungió con aceite perfumado los trenzados cabellos que, al moverse, provocaban la embriaguez de toda la tierra, a través del aire y del mar, a causa de la fragancia de largo alcance de aquel ungüento. Tenía en la cabeza una diadema de muy variado ornato, en la que había engarzados muchos rubíes, compañeros de séquito del Amor, los cuales, al agitarse, lanzaban la llama de Cípride en brillantes centelleos. Llevaba aquella famosa joya que arrastra a los hombres al deseo y que lleva el brillante nombre de Selene, que hiere con el deseo, la piedra encantadora del hierro que engendra el amor y la piedra amorosa de la India, pues también ésta brotó en las aguas a la vez que la Espumígena, y el oscuro jacinto, todavía amado por Febo. En torno a los bucles entrelazó la flor del Amor, a la que Citerea adora como a la propia rosa o la anémona, y la lleva cuando va a unirse con el hijo de Mirra. Se ciñó los flancos con el cesto, al que no estaba habituada. [...] Y se acercó a Zeus. En cuanto el rey de los cielos, Zeus, la vio, se apoderó de él el látigo del más ardiente deseo, espoleado por el aguijón del cesto. La mirada de Zeus -que la contemplaba- quedó esclavizada... "Querida esposa, deja la discordia a un lado. Que se quede mi valiente Dioniso segando la mies de la raza india que no conoce a Baco. Adiós. Que nos reciba ahora a los dos nuestro lecho nupcial, pues ningún deseo de otra amante terrestre ni divina ha enardecido mi ánimo tanto como ese ceñidor hechicero”. (Nonn., D., XXXII, 1-75)

Nono describe en detalle, igual que hacía Homero, la preparación de Hera para seducir a Zeus. En este caso, sin embargo, el texto amplía la información sobre el kestos himas de Afrodita, revelando que se trataba de una auténtica joya.

En su traducción de Dionisíacas, David Hernández de la Fuente (2004: 194) sostiene que todas las piedras preciosas que se mencionan, ligadas a este ornamento, tienen virtudes afrodisíacas. Nono habla, por un lado, del rubí, piedra que por su color rojo está relacionada con los asuntos del corazón; continúa después con la selenita, la piedra luna, vinculada a los ciclos femeninos y a las mujeres; la sigue la magnetita, descrita como "la piedra encantadora del hierro que engendra el amor"; ${ }^{12}$ habla después de "la piedra amorosa de la India" que, en este caso, se trata de la perla, gema relacionada con esta diosa porque, como ella, nace del mar y se le supone un poder erótico; por último, menciona al "oscuro jacinto", piedra que es más problemática de identificar pues Hernández de la Fuente la relaciona con el zafiro pero para Lisbet

\footnotetext{
${ }^{12}$ La magnetita es un óxido de hierro que, por su poder de atracción, fue muy utilizado para hechizos, amuletos y talismanes en la Antigua Grecia. Aparece, en varias ocasiones, ligada a Afrodita para atraer el amor.
} 
Thoresen (2017: 175-179) podría tratarse también de zircón, granate hessonita 0 alguna variedad de amatista.

Finalmente, disponemos de un texto mágico que alude a la joya de Afrodita y que describe también las gemas que portaba. Se trata del Kyranides que, en este caso, recoge tres kestos diferentes de la "gran diosa Afrodita, muy poderosa y capaz de cambiar las naturalezas de los humanos y de todos los animales, así como las inclinaciones de los machos, sobre todo de los humanos, de modo que cuando un varón toca o lleva (el amuleto) se hace débil y afeminado" (Perea Yébenes, 2010: 104105). El primero de ellos lleva engastada una obsidiana en la que, según se afirma, se debe grabar la imagen de un hombre castrado con los genitales a sus pies y, en el reverso, a Afrodita girando la cara para mirarlo. Los efectos para el hombre consistirán en que no tendrá erecciones o en que se volverá afeminado; y, para la mujer, que nadie tendrá cópula con ella pues los hombres que se le acerquen no tendrán erecciones. En este caso, en lugar de excitar el deseo sexual, los amuletos mencionados tienen el efecto contrario.

El segundo objeto que se describe y que "llevan las reinas" está compuesto por varias piedras: un lychnites o una ceraunia con la imagen de Ares armado. A los lados dos diamantes con una rosa silvestre de Afrodita, dos zafiros con Afrodita y Eros, dos homosardias ${ }^{13}$ con Helios y Selene, dos ágatas con Hermes y dos piedras de Némesis con esta sosteniendo una varita mágica y con el pie sobre una rueda.

Por último, se menciona una piedra luna que deberá llevarse alrededor del cuello y en la que "uno ve a la diosa, la Luna, aumentando y disminuyendo". Este talismán hace que, quien lo lleve, esté inspirado por la divinidad y sea adorado como un dios. "Muchos reyes lo llevan bajo su ropa u oculto en su diadema como un kestos, para que nadie lo vea. La piedra de la luna, como se ha dicho, tiene el mismo efecto cuando se lleva en un anillo" (Perea Yébenes, 2010: 104-105).

Así pues, el kestos himas de Afrodita es un ornamento mágico que lleva bordados diferentes sentimientos y emociones pero también una serie de gemas que tienen un efecto apotropaico, todas ellas diseñadas para tocar el corazón, atraer y excitar el deseo masculino o - en el caso del Kyranides - aplacarlo.

Campell Bonner (1949: 1-3) señala que este tipo de adorno es habitual en diosas del amor y de la fertilidad de la Antigüedad como Ishtar, Astarté, Atargatis o Afrodita. Además, recuerda también que, en esa época, se creía que las cuerdas, las bandas y los nudos podían usarse con fines mágicos, lo mismo que los arreglos en diagonal.

Claramente, la magia es un elemento de poder y el kestos himas es un objeto mágico como tantos otros que se vinculan con la diosa Afrodita y que están

\footnotetext{
${ }^{13}$ La homosardia es una piedra que aparece en varios lapidarios de la Antigüedad y que ha sido identificada con la sarda o con el ónix.
}

60

Lectora, 26 (2020): 49-65. ISSN: 1136-5781 D.O.I.: 10.1344/Lectora2020.26.4 
relacionados con sus poderes de seducción. También en los textos de magia griegos se documenta un encantamiento amoroso para doblegar el alma de otra persona y conducirla donde uno quiera. Dicho hechizo incluye de nuevo una magnetita, en este caso grabada con la imagen de Afrodita, Psique y Eros: "Una vez que la piedra esté grabada y consagrada, úsala de esta manera: ponla debajo de la lengua, dale una vuelta hasta que quieras y recita esta fórmula" (PGM, IV, 14, 1719 y ss.). Por lo tanto, en este caso, la gema grabada sustituiría al kestos himas, lo que nos hace pensar que dicho ornamento, en aras de la seducción, podía sustituirse por otro talismán mágico.

Vemos, en la figura 1, una escena referida a un episodio de la mitología cuyos protagonistas son Zeus, Afrodita y Eros. El dios solicita a Afrodita su intervención y ayuda para seducir a una mortal y ella le ofrece una iynx, un objeto en forma de rueda, recogido con varias cuerdas, que servía como un talismán de amor para la seducción. Así pues, aunque el himas era el más famoso, la diosa poseía diferentes objetos que estaban en relación con su poder de excitar el deseo y la pasión. Como afirma Christopher Faraone, "la magia erótica juega un papel prominente en muchos mitos griegos tempranos relacionados con las dinámicas de la seducción y el matrimonio" (1990: 219). Este autor considera que dichos mitos reflejarían la utilización de afrodisíacos en la

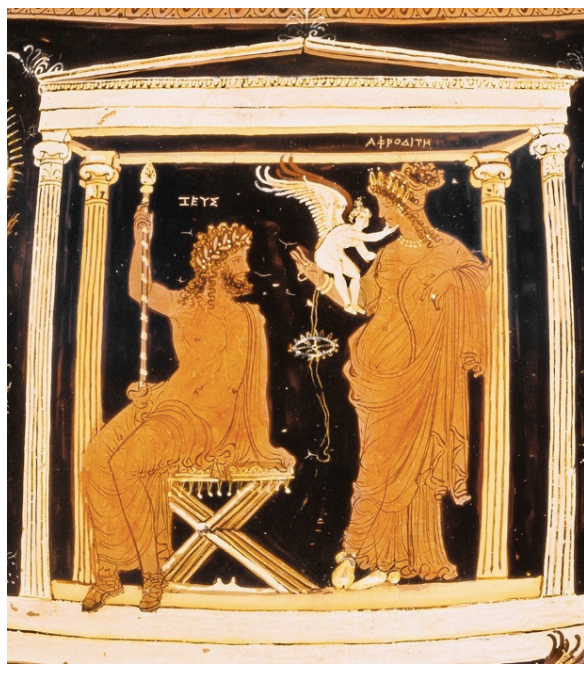

Fig. 1: Zeus, Afrodita y Eros. Lutróforo de Leda y el cisne (350-340 a.C.), Apulia. The J. Paul Getty Museum (Malibu 88.AE.680). Imagen tomada de www.getty.edu (8 de julio de 2018). cultura griega temprana.

Así pues, los sentimientos amorosos y su carga afectiva estuvieron, en Grecia, muy relacionados con las prácticas mágicas. Como apunta Pirenne-Delforge, "los modos de intervención de Afrodita y de sus seguidores pueden ser calificados de mágicos" (1994: 288), el kestos himas sería un ejemplo perfecto de ello. Teniendo en cuenta que, para los griegos, el amor podía llegar a ser una enfermedad, es lógico que dentro de su marco de referencia se incluyeran prácticas marginales ajenas a la religión oficial como el uso de amuletos, talismanes $\mathrm{u}$ otro tipo de objetos apotropaicos. 


\section{Conclusiones}

El imaginario griego clásico es a la vez complejo y fascinante. Divinidades y seres humanos se mezclan y se relacionan a través de cultos, rituales y prácticas mágicas, tras las que siempre existe una explicación argumentada. Entre todos los personajes de este extraordinario universo mitológico destaca Afrodita, la divinidad que tiene a su cargo las emociones relacionadas con la seducción y el amor.

Para poder realizar su cometido - que, en esta cultura, fue comparado con un combate-, la diosa dispone de una serie de herramientas - armas femeninas de seducción- entre las que destaca un objeto, la joya principal de Afrodita: el kestos himas. Surge aquí la pregunta sobre si el poder de atracción de la diosa era intrínseco a ella o estaba subordinado a la posesión de ciertos complementos mágicos.

Sea como sea, este ornamento cautivó tanto a los griegos que aludieron a él en numerosos fragmentos literarios, entre los que destaca el famoso Dios Apate o engaño de Hera para seducir a Zeus que aparece en la Ilíada. En él, la diosa utiliza el ornamento de Afrodita para subvertir el orden patriarcal establecido por Zeus; se trata, por lo tanto, de un objeto tan atractivo como peligroso.

Entre los siglos IV y V, Nono de Panópolis hará una descripción exhaustiva del mismo, en la que explicará que el kestos himas lleva engarzadas toda una serie de gemas relacionadas también con la atracción y el amor. Además, el tratado mágico conocido como Kyranides propondrá diversas versiones del mismo, así como su utilización con fines apotropaicos.

El kestos himas, la gran joya de Afrodita es, pues, un objeto de poder que tiene la capacidad de enloquecer los sentidos tanto de las divinidades como de los seres humanos. Frente a él no hay escapatoria posible y, cuando la diosa decide utilizarlo, el corazón de su víctima queda esclavizado, la voluntad paralizada, el deseo desbocado. Nadie como los griegos para describir la locura amorosa de forma tan atinada pero, a la vez, tan sugestiva.

\section{REFERENCIAS BIBLIOGRÁFICAS}

\section{Autores clásicos}

Antología Palatina II (2004), Guillermo Galán Vioque (trad.), Madrid, Gredos.

Aristides, Elio (1999), Discursos V, Juan Manuel Cortés (trad.), Madrid, Gredos.

Eliano; Teofilacto Simocates (1999), Cartas rústicas. Epístolas, Juan Manuel Cortés (trad.), Madrid, Gredos.

Hesíodo (1978), Obras y fragmentos, Aurelio Pérez Jiménez y Alfonso Martínez Díez (trads.), Madrid, Gredos.

62 
Himnos homéricos. La Batracomiomaquia (1978), Alberto Bernabé Pajares (trad.), Madrid, Gredos.

Homero (1991), Ilíada, Emilio Crespo Güemes (trad.), Madrid, Gredos.

Licofrón; Trifiodoro; Coluto (1987), Alejandra. La toma de Ilión. El rapto de Helena, Manuel y Emilio Fernández Galiano (trads.), Madrid, Gredos.

Lírica griega arcaica (1980), Francisco Rodríguez Adrados (trad.), Madrid, Gredos. Luciano (1988), Obras II, José Luis Navarro González (trad.), Madrid, Gredos.

Mitógrafos griegos: Paléfato. Heráclito. Anónimo Vaticano. Eratóstenes. Cornuto (2009), José B. Torres Guerra (trad.), Madrid, Gredos.

Nono de Panópolis (2004), Dionisíacas. Cantos XXV-XXXVI, David Hernández de la Fuente (trad.), Madrid, Gredos.

Platón (1968), Diálogos III, Carlos García Gual, Marcos Martínez Hernández, y Emilio Lledó Iñigo (trads.), Madrid, Gredos.

Plutarco (1986), Moralia II, Concepción Morales Otal y José García López (trads.), Madrid, Gredos.

Temistio (2000), Discursos políticos, Joaquín Ritoré Ponce (trad.), Madrid, Gredos.

Textos de magia en papiros griegos (1987), José Luis Calvo y María Dolores Sánchez (trads.), Madrid, Gredos.

The Greek Anthology (1969), W.R. Paton (trad.), Cambridge, Loeb Classical Library.

\section{Autores modernos}

Alzard Cerezo, Dunia (2013), Construcciones y estereotipos de feminidad reforzados a partir de la mitología clásica: el caso de Afrodita, Hera y Atenea, Tesis de máster, Madrid, Universidad Complutense de Madrid, 25/ 09/2013. $<$ http://eprints.ucm.es/26115/ >

Baring, Anne y Jules Cashford (2005), El mito de la diosa. Evolución de una imagen, Madrid, Siruela.

Bonner, Campbell (1949), "Kestos Imas and the Saltire of Aphrodite", The American Jornal of Philology, 70 (1): 1-6.

Breitenberger, Barbara (2007), Aphrodite and Eros. The Development of Erotic Mythology in Early Greek Poetry and Cult, Nueva York, Routledge.

Brenk, Frederick E. (1998), Relighting the Souls: Studies in Plutarch, in Greek Literature, Religion, and Philosophy, and in the New Testament Background, Stuttgart, Franz Steiner Verlag.

Brown, Arthur S. (1997), "Aphrodite and the Pandora Complex", The Classical Quarterly, 47 (1): 26-47

Burkert, Walter (2007), Religión griega arcaica y clásica, Madrid, Abada Editores. 
Butler, Judith (2010), Cuerpos que importan. Sobre los limites materiales y discursivos del sexo, Buenos Aires, Paidós.

Faraone, Christopher A. (1990), “Aphrodite's $\operatorname{KE} \Sigma T O \Sigma$ and Apples for Atalanta: Aphrodisiacs in Early Greek Myth and Ritual”, Phoenix, 44 (3): 219-243.

Flacelière, Robert (1971), L'amour en Grèce, París, Hachette.

Foucault, Michel (2003), Historia de la sexualidad 2: el uso de los placeres, Buenos Aires, Siglo XXI Editores.

Friedrich, Paul (1978), The Meaning of Aphrodite, Chicago, The University of Chicago Press.

Iriarte, Ana y Marta González (2010), Entre Ares y Afrodita. Violencia del erotismo y erótica de la violencia en la Grecia antigua, Madrid, Abada Editores.

Lee, Mireille M. (2015), Body, Dress and Identity in Ancient Greece, Nueva York, Cambridge UP.

López Jimeno, Amor (2000), "Maldiciones eróticas y otros encantamientos amorosos. La maldición del amor", Creencias y supersticiones en el mundo clásico y medieval: XIV Jornadas de Estudios Clásicos de Castilla y León, Manuel Antonio Marcos Casquero (coord.), León, Servicio de Publicaciones de la Universidad de León: 111-130.

Millett, Kate (1995), Política sexual, Ana María Bravo García (trad.), Madrid, Cátedra.

Mirón, María Dolores (2007), "Divina belleza: cuerpo femenino y poder en Grecia Antigua”, Cuerpos de mujeres: miradas, representaciones e identidades, Ana María Muñoz, Carmen Gregorio y Adelina Sánchez (eds.), Granada, Universidad de Granada: 167-187.

Perea Yébenes, Sabino (2010), "Magia, amuletos y supersticiones de materia médica en el libro I de Kyranides”, Edición de textos mágicos de la Antigüedad y de la Edad Media, Juan Antonio Álvarez-Pedrosa Núñez y Sofía Torallas Tovar (eds.), Madrid, CSIC: 91-143.

Pirenne-Delforge, Vinciane (1993), L'Aphrodite grecque. Contribution à l'étude de ses cultes et de sa personnalité dans le panthéon archä̈que et classique, Lieja, Kernos.

-(1994), "L'Iynge dans le discours mythique et les procédures magiques", Kernos: revue internationale et pluridisciplinaire de religion grecque antique, 6: 277-289.

Pironti, Gabriella (2005), “Aphrodite dans le domaine d'Ares. Éléments pour un dialogue entre mythe et culte", Kernos: revue internationale et pluridisciplinaire de religion grecque antique, 18: 167-184.

Redfield, James M. (2003), The Locrian Maidens. Love and Death in Greek Italy, Nueva Jersey, Princeton UP.

64

Lectora, 26 (2020): 49-65. ISSN: 1136-5781 D.O.I.: 10.1344/Lectora2020.26.4 
Rudhardt, Jean (1986), Le rôle d'Eros et d'Aphrodite dans les cosmogonies grecques, París, Presses Universitaires de France.

Thoresen, Lisbet (2017), “Archaeogemmology and Ancient Literary Sources on Gems and their Origins", Gemstones in the First Millennium AD. Mines, trade, workshops and symbolism, Alexandra Hilgner, Susanne Greiff y Dieter Quast (eds.), Maguncia, Verlag des Römisch-Germanischen Zentralmuseums.

\section{ABREVIATURAS}

Hes.

Hesíodo

Op.

Trabajos y días

Th.

Teogonía

h. Hom.

Himnos homéricos

h. Ven.

Himno a Afrodita

Hom.

Homero

Il.

Ilíada

Luc.

Luciano

Nonn.

Nono

D.

Dionisíacas

PGM

Textos de magia en papiros griegos

$\mathrm{Pl}$.

Platón

Smp.

Banquete

Plu.

Plutarco

Mor.

Moralia

Sapph.

Safo 